\title{
Exercise-Induced Bronchospasm in Soccer Athletes Living in a Tropical Humid Region
}

Rodrigo Luis Mousinho Gomes ${ }^{1}$, Edil de Albuquerque Rodrigues Filho ${ }^{2}$, Marco Aurélio de Valois Correia Júnior ${ }^{1,3}$, Gilmário Ricarte Batista ${ }^{3}$, Anderson Henrique Souza de Almeida ${ }^{1}$ and José Ângelo Rizzo ${ }^{1,2^{*}}$

${ }^{1}$ Health Sciences Center, Federal University of Pernambuco, Recife, Brazil

${ }^{2}$ Child Adolescent Health, Federal University of Pernambuco, Recife, Brazil

${ }^{3}$ Federal University of Pernambuco, Recife, Brazil

${ }^{4}$ Federal University of Paraiba, João Pessoa, Brazil

"Corresponding author: Rizzo JA, Health Sciences Center, Federal University of Pernambuco, Recife, Brazil, Tel: +81-986994098; E-mail: jarizzo@hotlink.com.br Received date: December 13, 2017; Accepted date: January 27, 2018; Published date: February 07, 2018

Copyright: (c) 2018 Gomes RLM, et al. This is an open-access article distributed under the terms of the Creative Commons Attribution License, which permits unrestricted use, distribution and reproduction in any medium, provided the original author and source are credited.

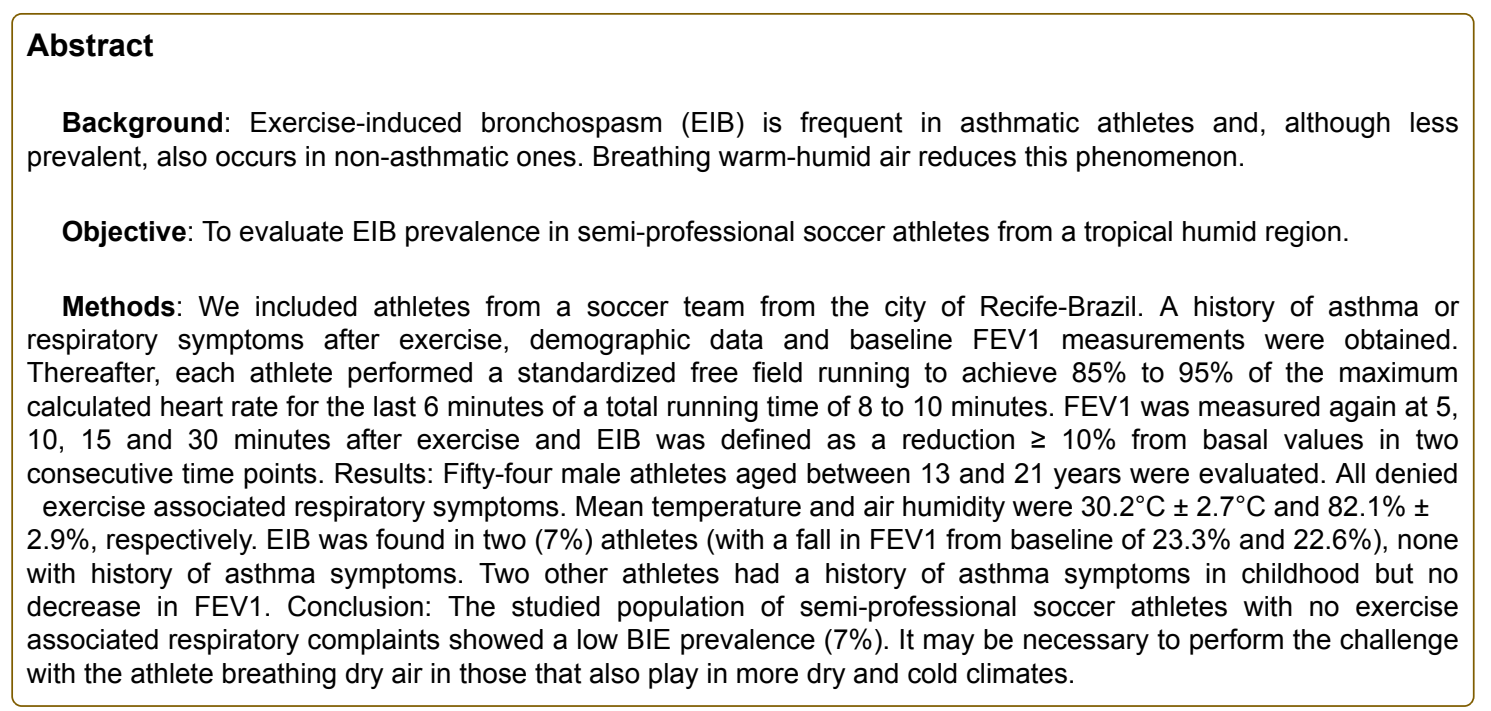

Keywords: Asthma; Athletes; Soccer; Exercise-induced bronchospasm; Exercise

\section{Introduction}

Exercise-induced bronchospasm (EIB) is the transitory narrowing of lower respiratory airways which occurs during, or more often, after vigorous physical activity [1,2]. It is found in high proportion of asthmatic children and adolescents and among asthmatic athletes EIB is diagnosed in up to $90 \%$ of them, varying with the adopted diagnostic protocol, exercise intensity and breathing air conditions [3-5]. Depending on sport modality and the diagnostic protocol adopted, the prevalence of EIB in non-asthmatic elite athletes varies from $8 \%$ to $50 \%$ [6-8].

Self-reported respiratory symptoms after strenuous exercise is a common complaint in athletes but are deemed as non-reliable for EIB diagnosis $[9,10]$. In elite athletes the lack of adequate EIB recognition and prevention could impair maximal physical performance [11] and it is recommended that those who report respiratory symptoms should perform objective diagnostic tests to guide a correct diagnosis, a more appropriate training schedule and the pharmacological prevention [12].
Inherent personal factors such as atopy, allergic rhinitis and asthma, as well as ambient air conditions such as low temperature and relative humidity, can directly influence EIB triggering [13]. In asthmatic adolescents it has been shown that EIB prevalence drops by half after free running tests carried out in the summer when compared to winter in countries with well-defined climatic seasons [14].

Soccer is extensively played all over the world by amateurs, semiprofessionals or professionals athletes. In spite the fact that soccer is an Olympic sport and its World Cup has the largest world's sports audience, limited information is found in the literature regarding the prevalence of EIB in professional or semi-professional soccer players $[3,12,15-17]$. The objective of this research was to prospectively screen a sample of semi-professional athletes of a soccer team from Recife - a Brazilian city characterized by a tropical humid climate for the prevalence of EIB using a field running protocol.

\section{Materials and Methods}

Participants were semi-professional athletes from the lower division of a professional Brazilian soccer team - Clube Nautico Capibaribe located at the city of Recife, an estuarine city located on the northeast Brazilian coast $\left(-08^{\circ} 04^{\prime} 03^{\prime \prime} \mathrm{S}, 34^{\circ} 55^{\prime} 00^{\prime \prime} \mathrm{W}\right)$ that has temperatures ranging between $23^{\circ} \mathrm{C}$ and $32^{\circ} \mathrm{C}$ and a relative air humidity oscillating between $70 \%$ and $85 \%$, with small changes along the year. The athletes 
had physical and technical training sessions from Monday through Friday, at least three hours each day. The exclusion criteria were the reporting of recent symptoms of respiratory infection (less than three months), forced expiratory volume in one second (FEV1) below $80 \%$ of predicted, and inability to adequately perform an acceptable forced expiratory maneuver. The study was approved by the institutional ethics committee on human research and all individuals who participated in the study signed an informed consent form. The diagnosis of asthma compatible symptoms was done using the International Study of Asthma and Allergies in Childhood (ISAAC) questionnaire translated and validated for Brazil [18], which was administered to each of the athletes separately. The medical records of each participant were also reviewed.

Temperature and relative air humidity were recorded before exercise (TEMP Int/Ext, Cotronic Technology Ltd, Hong Kong, China), and anthropometric measurements were taken using a calibrated scale (model 111 class III, Balmak, São Paulo, Brazil) and a portable stadiometer (American Medical do Brasil, São Paulo). Spirometric parameters were measured according to the international criteria of standardization and acceptability of tests [19], employing a daily calibrated spirometer (WinDxTM Revelation, Creative BioMedics San Clemente, CA, USA).

Physical exercise test was done by free field running in a $10 \times 20$ meters rectangle previously marked with cones in the soccer field. Two co-workers were placed at two corners in diagonal position to stimulate the athletes to maintain or change the rhythm to keep the target heart rate. The test duration was 8 to 10 minutes with a progressive speed increase for warm-up on the first two minutes and in the last six minutes to maintain the heart rate between 85 to $95 \%$ of maximum calculated [20].

Spirometry was conducted in duplicate before and 5, 10, 15 and 30 minutes after the run and the best FEV1 recorded at each time point. The test was considered positive if a fall in FEV1 of $\geq 10 \%$ was observed over two consecutive time points compared with baseline and the biggest chosen for analysis [20]. The predicted values were those for Brazilians [21].

\section{Results}

Fifty-four male athletes were evaluated between the months of April to June - the most humid of the year. Subjects' characteristics such as age, anthropometric measures, and mean baseline predicted FEV1 are presented in Table 1. Only two athletes reported having asthma in childhood but no actual respiratory symptoms, while the others denied any respiratory symptom or asthma diagnosis. No athlete was excluded on the basis of the exclusion criteria.

\begin{tabular}{|c|c|c|c|c|}
\hline Age range & $\mathbf{n}(\%)$ & Height $(\mathbf{m})$ & Weight $(\mathbf{K g})$ & Baseline FEV1 \\
\hline & & (Mean + SD) & (Mean + SD) & (Mean + SD) \\
\hline 13 to 15 years & $18(33 \%)$ & $1.70 \pm 0.09$ & $60.77 \pm 12.29$ & $105.99 \pm 12.67$ \\
\hline 16 to 18 years & $30(55 \%)$ & $1.73 \pm 0.07$ & $66.56 \pm 8.55$ & $102.96 \pm 9.88$ \\
\hline 19 to 21 years & $6(11 \%)$ & $1.85 \pm 0.06$ & $73.83 \pm 4.16$ & $95.43 \pm 5.06$ \\
\hline \multicolumn{2}{|r|}{ * }
\end{tabular}

Table 1: Characteristics of the studied sample.
Tests were performed between 2 and 4 pm under $30.2^{\circ} \mathrm{C} \pm 2.7^{\circ} \mathrm{C}$ mean temperature and a relative air humidity of $82.1 \% \pm 2.9 \%(\sim 24 \mathrm{~g}$ of water /liter of air). Mean achieved heart rate was $89.5 \pm 4.7 \%$ of the maximum calculated.

After running, two athletes (15 and 17 years old) showed fall in FEV1 in two measured time points compared to basal values (7\%), the maximum fall were of $23.3 \%$ and $22.6 \%$ respectively, none of them complained of exercise related respiratory symptoms or had a diagnostic history of asthma.

\section{Discussion}

Our results showed a low prevalence of EIB (7\%) among 54 soccer players with no exercise related respiratory complaints in a tropical and humid climate city submitted to a standardized field-based running.

Guidelines recommend exercise intensity to reach and keep heart rate between $85 \%$ and $90 \%$ of maximum calculated [20]. All the studied athletes reached at least $85 \%$ of maximum calculated heart rate during the last six minutes of running. The adopted spirometry acceptability criteria [19] and the stricter diagnostic criteria of a fall of $>10 \%$ at two consecutive time points [20] minimized bias as a possible cause for the observed results. Furthermore, the challenge stimulus for EIB diagnosis that utilize exercise in the field, similar to the athlete's sport activity, are considered valid and even more efficient than those done in the laboratory with controlled environment temperature and humidity [8]. It is possible that if the exercise challenges were done with athletes breathing dry air this prevalence would be higher.

The prevalence of respiratory symptom among elite athletes is high [22] and exercises of long duration with high loads, requiring high ventilation levels, are those that most often cause EIB [23-25]. It is believed that the mechanism responsible for EIB is airway periciliary fluid dehydration due to hyperventilation that leads to mediators release by airway epithelial and mast cells [26]. Environmental conditions such as low temperature and relative humidity, together with increased breathing rates and exposure to irritants, as well as aeroallergens and suspended air pollutants, strongly contribute to EIB triggering in athletes [27]. It is also relevant that even in non-asthmatic athletes the aggression caused by these repeated and prolonged stimuli -especially chlorine in swimming pools - result in an increase in the number of bronchial mucosa inflammatory cells (especially neutrophils and/or eosinophils) and in bronchial hyperresponsiveness [28]. Discontinuation of the physical activities leads to the reduction or gradual disappearance of these phenomena [29]. The presence of asthma or atopy potentiates all those factors [8].

Studies have investigated the prevalence of EIB in athletes without known history of asthma. In a sample of 212 athletes of different sports in a training facility who had no prior asthma diagnosis, 20 (9\%) showed $>10 \%$ fall in FEV1 from basal values after eucapnic voluntary hyperventilation (EVH) [30]. Among 198 British Olympic athletes submitted to EVH test who did not have a previous diagnosis of asthma or bronchial hyperresponsiveness, Dickinson and colleagues [31] demonstrated a FEV1 reduction $>10 \%$ from basal in $29 \%$ of them. The lower EIB prevalence observed in our sample (7\%) may be related to temperature and humidity conditions of breathed air in RecifeBrazil. It is possible that if exposed to drier and/or colder air temperatures a greater proportion of those athletes would have an EIB diagnosis. 
Soccer is a sport that imposes a high aerobic load demanding that, particularly close to competitions, the athletes reach their best physical conditioning that requires an increase in extent and intensity of trainings. During a professional soccer game some athletes run as much as 10 to $15 \mathrm{~km}$. Few studies were found in the literature that have evaluated the presence of EIB in participant of this sport, despite the difficulties with the terms soccer and football to designate the sport as understood by FIFA (Féderatión Internationale de Football Association). SØdal [32] found a prevalence of $35 \%$ for bronchial hyperresponsiveness in soccer players of a national female team in Norway. In Iranian children who played soccer, Ziaee et al. [17] noted an EIB prevalence of $6 \%$, but the challenge was made through a game of soccer lasting 15 minutes, which could have been insufficient to reach the exercise load considered adequate [20]. Other investigators found an EIB prevalence of $11 \%$ among soccer playing children aged 8 to 13 years without previous asthma diagnosis $[33,34]$.

In Tehran, Iran, a prevalence of $6 \%$ in non-asthmatic athletes was found in 100 adult players from a soccer team [16]. The temperature conditions were similar to ours, but relative humidity was lower, between 18 and 51\%. The diagnostic criterion of EIB was a $15 \%$ reduction in FEV1, which could have also underestimated the prevalence. The type of physical activity used for provocation was not specified in that study.

Until 2010 regulatory anti-doping agencies required that asthma or EIB among athletes should be proven by objective methods before requesting authorization for the use of preventive medication. WADA (World Anti-doping Agency) new list of allowed medications permits the use of albuterol and salmeterol since 2010 and formoterol since 2013 without clinical confirmation, requiring a notification only. Inhaled corticoids are also allowed [35].

It is necessary to emphasize that the diagnosis of EIB in athletes with exercise associated respiratory symptoms or a diagnosis of asthma should be made by an objective test. Ansley et al. [12] showed that of the 65 English professional soccer players diagnosed as asthmatics that they evaluated, 57 made regular use of medication to prevent EIB and, despite reporting complaints of respiratory symptoms during exercise, only 31 had a positive response after the bronchoprovocation by EVH and/or inhalation of mannitol, and the symptoms were not predictors of bronchial responsiveness to the bronchial provocation tests [12].

Although it may seem intuitive that EIB could impair athletic performance, especially in elite athletes, this by no means is a settled question [11]. The two patients that showed a fall in FEV1 of more than $20 \%$ from baseline had no respiratory complaints or reported any trouble in doing their training physical activities. Some sports organizations have established EIB screening programs for all of their internationally competitive athletes but this is far from being a consensus [35]. On the other hand, it is clear that individuals with exercise associated respiratory complaints and/or a clinical diagnosis of asthma that are engaged in competitive sportive activities should be evaluated for EIB $[3,8,9,12,15,20,24,35]$.

\section{Conclusion}

It is odd that so few studies are reported in the literature on diagnosis and prevention of EIB among soccer athletes. As this is the world's most widespread and popular sport that is held outdoors, more studies are needed to evaluate EIB prevalence among soccer players, its association with respiratory complaints, asthma, allergic and non- allergic rhinitis, the influence of different climate conditions and prevention.

\section{Conflict of Interests}

None declared.

\section{References}

1. McFadden JE (1995) Exercise-induced airway obstruction. Clin Chest Med 16: 671-682.

2. Beck KC, Joyner MJ, Scanlon PD (2002) Exercise-induced asthma: Diagnosis, treatment, and regulatory issues. Exerc Sport Sci Rev 30: 1-3.

3. Carlsen KH, Anderson SD, Bjermer L, Bonini S, Brusasco V, et al. (2008) Exercise-induced asthma, respiratory and allergic disorders in elite athletes: epidemiology, mechanisms and diagnosis: part I of the report from the Joint Task Force of the European Respiratory Society (ERS) and the European Academy of Allergy and Clinical Immunology (EAACI) in cooperation with GA2LEN. Allergy 63: 387-403.

4. Anderson SD, Pearlman DS, Rundell KW, Perry CP, Boushey H, et al. (2010) Reproducibility of the airway response to an exercise protocol standardized for intensity, duration, and inspired air conditions, in subjects with symptoms suggestive of asthma. Respir Res 11: 120.

5. Rundell KW, Jenkinson DM (2002) Exercise-induced bronchospasm in the elite athlete. Sports Med 32: 583-600.

6. Langdeau JB, Boulet LP (2001) Prevalence and mechanisms of development of asthma and airway hyperresponsiveness in athletes. Sports Med 31: 601-616.

7. Uçok K, Dane S, Gökbel H, Akar S (2004) Prevalence of exercise-induced bronchospasm in long distance runners trained in cold weather. Lung 182: 265-270.

8. Rundell KW, Slee JB (2008) Exercise and other indirect challenges to demonstrate asthma or exercise-induced bronchoconstriction in athletes. J Allergy Clin Immunol 122: 238-246.

9. Parsons JP, Mastronarde JG (2005) Exercise-induced bronchoconstriction in athletes. Chest 128: 3966-3974.

10. Holzer K, Douglass JA (2006) Exercise induced bronchoconstriction in elite athletes: measuring the fall. Thorax 61: 94-96.

11. Price OJ, Hull JH, Backer V, Hostrup M, Ansley L (2014) The impact of exercise-induced bronchoconstriction on athletic performance: A systematic review. Sports Med. 44: 1749-1761.

12. Ansley L, Kippelen P, Dickinson J, Hull JH (2012) Misdiagnosis of exercise-induced bronchoconstriction in professional soccer players. Allergy 67: 390-395.

13. Sacha JJ, Quinn JM (2011) The environment, the airway, and the athlete. Ann Allergy Asthma Immunol 106: 81-87.

14. Goldberg S, Schwartz S, Izbicki G, Hamami RB, Picard E (2005) Sensitivity of exercise testing for asthma in adolescents is halved in the summer. Chest 128: 2408-2411.

15. Parsons JP, Cosmar D, Phillips G, Kaeding C, Best TM, et al. (2012) Screening for exercise-induced bronchoconstriction in college athletes. J Asthma 49: 153-157.

16. Zahmatkesh MM, Ehteshami AA, Asadian A (2002) Exercise-induced bronchospasm in soccer players. Tanaffos 1: 35-39.

17. Ziaee V, Yousefi A, Movahedi M, Mehrkhani F, Noorian R (2007) The prevalence of exercise-induced bronchospasm in soccer player children, ages 7 to 16 years. Iran J Allergy Asthma Immunol 6: 33-36.

18. Solé D, Cassol VE, Silva AR, Teche SP, Rizzato TM, et al. (2007) Prevalence of symptoms of asthma, rhinitis, and atopic eczema among adolescents living in urban and rural areas in different regions of Brazil. Allergol Immunopathol (Madr) 35: 248-253.

19. Miller MR, Hankinson J, Brusasco V, Burgos F, Casaburi R, et al. (2005) Standardisation of spirometry. Eur Respir J 26: 319-338.

20. Weiler JM, Anderson SD, Randolph C, Bonini S, Craig TJ, et al. (2010) Pathogenesis, prevalence, diagnosis, and management of exercise- 
Citation: Gomes RLM, Filho EAR, Júnior MAVC, Batista GR, Almeida AHS, et al. (2018) Exercise-Induced Bronchospasm in Soccer Athletes Living in a Tropical Humid Region. J Sports Med Doping Stud 8: 200. doi:10.4172/2161-0673.1000200

Page 4 of 4

induced bronchoconstriction: a practice parameter. Ann Allergy Asthma Immunol 105: S1-47.

21. Pereira CA, Sato T, Rodrigues SC (2007) New reference values for forced spirometry in white adults in Brazil. J Bras Pneumol 33: 397-406.

22. Turcotte H, Langdeau JB, Thibault G, Boulet LP (2003) Prevalence of respiratory symptoms in an athlete population. Respir Med 97: 955-963.

23. Helenius I, Lumme A, Haahtela T (2005) Asthma, airway inflammation and treatment in elite athletes. Sports Med 35: 565-574.

24. Pedersen L, Lund TK, Barnes PJ, Kharitonov SA, Backer V (2008) Airway responsiveness and inflammation in adolescent elite swimmers. J Allergy Clin Immunol 122: 322-327.

25. Lund TK (2009) Asthma in elite athletes: How do we manage asthma-like symptoms and asthma in elite athletes? Clin Respir J 3: 123.

26. Anderson SD, Daviskas E (2000) The mechanism of exercise-induced asthma is... J Allergy Clin Immunol 106: 453-459.

27. Helenius I, Haahtela T (2000) Allergy and asthma in elite summer sport athletes. J Allergy Clin Immunol 106: 444-452.

28. Anderson SD, Kippelen P (2008) Airway injury as a mechanism for exercise-induced bronchoconstriction in elite athletes. J Allergy Clin Immunol 122: 225-235.

29. Helenius I, Rytilä P, Sarna S, Lumme A, Helenius M, et al. (2002) Effect of continuing or finishing high-level sports on airway inflammation, bronchial hyperresponsiveness, and asthma: a 5-year prospective follow- up study of 42 highly trained swimmers. J Allergy Clin Immunol 109: 962-968.

30. Mannix ET, Roberts M, Fagin DP, Reid B, Farber MO (2003) The prevalence of airways hyperresponsiveness in members of an exercise training facility. J Asthma 40: 349-355.

31. Dickinson J, McConnell A, Whyte G (2011) Diagnosis of exerciseinduced bronchoconstriction: Eucapnic voluntary hyperpnoea challenges identify previously undiagnosed elite athletes with exercise-induced bronchoconstriction. Br J Sports Med 45: 1126-1131.

32. Sødal A (1997) Bronchial hyperreactivity, exercise induced asthma and allergy. A study of female national team athletes in soccer. Norwegian University of Sport and Physical Education.

33. Sidiropoulou M, Tisimaras V, Fotiadou E, Aggelopoulou-Sakadami N (2005) Exercised-induced asthma in soccer players ages from 8 to 13 years. Pneumologie 59: 238-243.

34. http://www.wada-ama.org/Documents/Science_Medicine/ Medical_info_to_support_TUECs/WADA-Medical-info-Asthma-5.0EN.pdf

35. Parsons JP, Hallstrand TS, Mastronarde JG, Kaminsky DA, Rundell KW et al. (2013) An official American Thoracic Society clinical practice guideline: exercise-induced bronchoconstriction. Am J Respir Crit Care Med 187: 1016-1027. 